\title{
ANÁLISE DOS CRITÉRIOS PARA UMA EDUCAÇÃO PERSONALIZADA EM ARTIGOS DA ÁREA DE ENSINO PUBLICADOS ENTRE 2010-2020
}

\author{
Nayara de Lima Oliveira ${ }^{1}$ \\ Bruno Silva Leite 2
}

\begin{abstract}
RESUMO
A personalização tem o intuito de tornar o estudante protagonista da sua aprendizagem, podendo ele criar, vivenciar e modificar o processo educacional, de modo a aprender como, quando e onde quiser. Nesse sentido, esta pesquisa exploratória, de cunho bibliográfica, teve como objetivo investigar características de uma educação personalizada nas publicações da área de Ensino no período entre 2010 a 2020 que tratam sobre o ensino híbrido, analisando se as propostas presentes nos artigos atendem aos critérios estabelecidos por Hoz (2018) sobre educação personalizada (singularidade, autonomia, liberdade, abertura e comunicação). A partir de perguntas guias foi possível analisar e identificar os critérios presentes nos artigos. Os resultados mostram um número pequeno de trabalhos que envolvem a temática da personalização no ensino híbrido e que apenas três apresentam todos os critérios de um ensino personalizado. Além disso, foi possivel identificar ações que resultaram em um ensino personalizado e que apontam caminhos para que professores possam personalizar suas aulas.
\end{abstract}

Palavras-chave: Educação Personalizada. Ensino Híbrido. Revisão bibliográfica.

\section{ANALYSIS OF THE CRITERIA FOR PERSONALIZED EDUCATION IN ARTICLES IN THE AREA OF TEACHING PUBLISHED BETWEEN 2010-2020}

\begin{abstract}
Personalization aims to make the student the protagonist of his learning, being able to create, experience, and modify the educational process, in order to learn how, when, and where he wants. In this sense, this exploratory research, bibliographical nature, had as objective to investigate characteristics of personalized education in the publications of the Teaching area in the period from 2010 to 2020 that deal with blended learning, analyzing if the proposals present in the articles meet the established criteria by Hoz (2018) on personalized education (uniqueness, autonomy, freedom, openness, and communication). From guiding questions it was possible to

\footnotetext{
${ }^{1}$ Mestranda em Ensino das Ciências, Universidade Federal Rural de Pernambuco, Programa de Pós-graduação em Ensino das Ciências, Recife, PE, Brasil; Grupo LEUTEQ (Laboratório para Educação Ubíqua e Tecnológica no Ensino de Química). Orcid iD: https://orcid.org/0000-0002-1627-6621. E-mail: quimicanayara7@gmail.com

2 Doutorado em Química Computacional. Professor da Universidade Federal Rural de Pernambuco, Recife, PE, Brasil; Coordenador do Grupo LEUTEQ (Laboratório para Educação Ubíqua e Tecnológica no Ensino de Química). Orcid iD: http://orcid.org/0000-0002-9402-936X. E-mail: brunoleite@ufrpe.br
} 
analyze and identify the criteria present in the articles. The results show a small number of studies that involve the theme of personalization in a hybrid education and that only three present all the criteria of personalized teaching. Also, it was possible to identify actions that resulted in personalized teaching, and that point out ways for teachers to personalize their classes.

Keywords: Personalized Education. Blended Learning. Literature review.

\section{ANÁLISIS DE LOS CRITERIOS DE EDUCACIÓN PERSONALIZADA EN ARTÍCULOS EN EL ÁREA DE ENSEÑANZA PUBLICADOS ENTRE 2010-2020}

\section{RESUMEN}

La personalización tiene como objetivo hacer que los estudiantes sean los protagonistas de su aprendizaje, y puedan crear, experimentar y modificar el proceso educativo, para aprender cómo, cuándo y dónde quieran. En este sentido, esta investigación exploratoria, de carácter bibliográfico, tuvo como objetivo indagar en las características de la educación personalizada en las publicaciones del área Docente en el período 2010 a 2020 que abordan la educación híbrida, analizando si las propuestas en los artículos cumplen con los criterios establecidos de Hoz (2018) sobre educación personalizada (singularidad, autonomía, libertad, apertura y comunicación). A partir de preguntas orientadoras, fue posible analizar e identificar los criterios presentes en los artículos. Los resultados muestran un pequeño número de estudios que involucran el tema de la personalización en la enseñanza híbrida y que solo tres presentan todos los criterios de la enseñanza personalizada. Fue posible identificar acciones que resultaron en una enseñanza personalizada y que señalan formas para que los docentes personalicen sus clases.

Palabras clave: Educación personalizada. Enseñanza híbrida. Revisión bibliográfica.

\section{INTRODUÇÃO}

As críticas que são realizadas ao ensino tradicional não são recentes, principalmente porque, na maioria das vezes, esse tipo de ensino é considerado vertical, tendo o professor como o único detentor de todos os conhecimentos e os estudantes como meros receptores desse conhecimento. Os esforços para ajustar a ação educativa às necessidades e interesses dos estudantes está cada vez mais frequente e se manifestam na busca intensa por um planejamento e pospostas metodológicas que possam situar o estudante no centro do processo educativo (COLL, 2018; LEITE, 2018). Através desse pensamento e ação (de trazer o estudante para o centro da aprendizagem) que surgiu o que tem sido denominado de metodologias ativas. 
As metodologias ativas buscam dar ênfase ao protagonismo do estudante e ao seu envolvimento direto, participativo, reflexivo e crítico em todas as etapas da construção do conhecimento. Nessas metodologias o estudante pode experimentar, desenhar, criar e se tornar autônomo durante o processo de aprendizagem, em que o professor tem o papel de mediador, mostrando os caminhos para que os estudantes sejam guiados $(\mathrm{BAClCH}$; MORAN, 2018; LEITE, 2018).

No intuito de tornar o estudante protagonista de sua aprendizagem surge o ensino híbrido, como uma metodologia capaz de mesclar o ensino presencial com o ensino on-line e assim levar o melhor das duas realidades para desenvolver uma aprendizagem mais significativa, participativa e personalizada. A inserção das tecnologias digitais na educação, em especial no ensino híbrido, tem possibilitado o seu uso em sala de aula, permitindo a customização (personalização) de diversos setores para contribuir no processo de ensino e aprendizagem. Por exemplo, no ensino on-line os estudantes podem aprender a qualquer momento, lugar e ritmo. Além disso, os estudantes podem avançar (se já dominarem), pausar (se precisarem assimilar) ou retroceder (se precisarem revisar) um determinado conceito (VOLTZ et al., 2019).

A aprendizagem deve estar centralizada no estudante, para conduzir assim, uma personalização do ensino (KNAUTH, 2018). Destarte, é necessário entender que não basta a presença física dos estudantes e o cumprimento das tarefas de forma mecânica para uma educação de qualidade. É necessário que tanto os estudantes quanto docentes estejam engajados e organizados de acordo não apenas com os objetivos das disciplinas e instituições, mas de acordo com seus objetivos de vida e de forma crítica, apenas assim, poderão transformar seus contextos (VOLTZ et al., 2019). É diante dessa realidade, que deve ser vivenciada em sala de aula, que faça sentido para o estudante, que emergem as discussões sobre a personalização do ensino ou educação personalizada.

A personalização ou educação personalizada no seu sentido mais profundo não se encontra em uma forma ou um método novo de ensino 
mais eficaz, mas na transformação do aprendizado num elemento de formação pessoal mais significativo através da adaptação e escolha de responsabilidades por parte do próprio estudante (HOZ, 2018).

Discutir sobre a educação personalizada se faz importante no contexto atual do estudante do século XXI, em que este tem a oportunidade de personalizar sua aprendizagem sendo incentivado nos ambientes educativos. Considerando os pressupostos defendidos por Hoz (2018) como essenciais para a personalização (singularidade, autonomia, liberdade, abertura e comunicação), esta pesquisa tem como objetivo investigar características de uma educação personalizada nas publicações de periódicos da área de Ensino da CAPES no período entre 2010 a 2020 que tratam sobre o ensino híbrido. Analisando se as propostas presentes nos artigos atendem aos critérios estabelecidos por Hoz (2018) sobre educação personalizada, indicando a presença ou ausência da personalização.

\section{Personalização e Educação Personalizada}

A primeira menção sobre personalização foi realizada em meados de 1905, por Helen Parkhurst que criou o plano Dalton (PARKHURST, 1926). Parkhurst ao ter que ministrar aulas para várias turmas ao mesmo tempo, precisou dividir as turmas em pequenos grupos e cada grupo se dedicava a estudar disciplinas específicas. Assim, os estudantes poderiam estudar de acordo com seu ritmo, sempre trabalhando em cooperação com os colegas. Desse modo, Parkhurst apresentou os princípios de uma abordagem individual para a avaliação de resultados (GUZIK, 2016).

No ano de 1970 o conceito de personalização se tornou popular com o pedagogo espanhol Vítor Garcia Hoz que elaborou, junto com outros autores, O Tratado de Educación Personalizada (1990). Nessa obra estão descritas as reflexões e ideias sobre a educação personalizada e a importância do papel da família na escola para formação do sujeito. Segundo Hoz (2018), a educação personalizada não é um método de ensino, mas uma concepção educativa, com exigências práticas, cujo fundamento é o conceito de pessoa. Para Guzik (2016) a personalização 
pressupõe que os próprios estudantes podem criar, vivenciar e modificar o processo educacional, eles decidem que caminho percorrer, tornando-os independentes e conscientes, ensinando-os a ajudar a si mesmos. Já Coll (2018) aponta que a personalização se conecta diretamente com a tradição das pedagogias centradas no estudante, e com as abordagens e propostas construtivistas da educação. Na personalização, os estudantes são protagonistas em todo o processo educativo e isso acontece na medida em que a escola reconhece e se estrutura para atender diversos perfis de aprendizagem (LIMA-JÚNIOR, 2018).

É importante destacar que a ideia de educação personalizada dialoga com as propostas de Freire (1996). Segundo Nunes (2017), as obras de Freire refletem uma concepção de um homem que se permite refletir, reelaborar e reescrever sua vida e esses aspectos são vislumbrados nas ideias de Hoz (1990). Na literatura há uma diversidade de conceitos que impedem apresentar uma única definição para educação personalizada $(\mathrm{HOZ}, 1990$, 2018; GUZIK, 2016; COLL, 2018; LIMA-JÚNIOR, 2018). Neste trabalho optamos por adentrar na perspectiva de educação personalizada apontada por Hoz (2018).

Quando se fala em personalização do ensino deve-se ter em mente que é uma adequação do modo e da forma como aquele estudante aprende de acordo com suas necessidades, por outro lado, levando em consideração as competências que podem ser adquiridas a partir dessa personalização. Segundo Knauth (2018), a aprendizagem deve estar centralizada no estudante, para conduzir assim, uma personalização do ensino. Em suas pesquisas Hoz (2018) apresenta critérios fundamentais que podem categorizar a educação como personalizada: Singularidade, Criatividade, Autonomia, Liberdade, Abertura e Comunicação. Estes critérios são brevemente descritos no Quadro 1. 
QUADRO 1 - Critérios para uma educação personalizada

\begin{tabular}{|c|c|}
\hline Critério & Característica \\
\hline Singularidade & $\begin{array}{l}\text { É o que constitui a essência do sujeito, que implica não somente na } \\
\text { separação real e diferenciação numérica, ou seja, o que ele } \\
\text { realmente é e o que o difere numericamente dos demais, mas a } \\
\text { distinção qualitativa em virtude do que cada sujeito é, quem é e } \\
\text { como isso o difere dos demais. A educação do ponto de vista da } \\
\text { singularidade deve fazer o sujeito consciente qualitativamente e } \\
\text { quantitativamente de suas próprias possibilidades e limitações. Em sala } \\
\text { de aula é preciso principalmente que o professor entenda que está } \\
\text { em um ambiente totalmente heterogêneo de contextos, vivências, } \\
\text { histórias e emoções e deve levar isso em consideração, não } \\
\text { individualizando o processo, mas permeando todas as formas de } \\
\text { aprendizagens possíveis. }\end{array}$ \\
\hline Criatividade & $\begin{array}{l}\text { O desenvolvimento da originalidade ou da capacidade criativa é um } \\
\text { princípio unificador do processo educativo. Ser original é ser criador, a } \\
\text { originalidade e a criatividade se encontram estreitamente vinculadas. } \\
\text { Para que a criatividade se desenvolva, é necessário a criação de um } \\
\text { ambiente desafiador. A sala de aula, por exemplo, pode e deve ser } \\
\text { um ambiente que desafie os estudantes a criarem coisas e para esse } \\
\text { processo cabe uma postura de professor incentivador e desafiador } \\
\text { que permite nesse espaço escolar, a resolução de problemas de } \\
\text { forma criativa. }\end{array}$ \\
\hline Autonomia & $\begin{array}{l}\text { É a capacidade do governo de si mesmo, a capacidade de ser lei de } \\
\text { si mesmo, a possessão e o uso efetivo da liberdade. Na busca pela } \\
\text { autonomia do estudante é preciso entender que ele precisa seguir por } \\
\text { si próprio, mas quando dúvidas surgem ao longo desse percurso, a } \\
\text { professor pode estar presente para discutir suas escolhas. }\end{array}$ \\
\hline Liberdade & $\begin{array}{l}\text { Apresenta dois sentidos: 1) ao sentimento de independência com } \\
\text { referência aos possíveis obstáculos que impediriam a ação de se } \\
\text { expressar como liberdade de; 2) capacidade de autodeterminar } \\
\text { nossas ações, de escolher em cada momento o modo de agir e se } \\
\text { expressa comoliberdade para. }\end{array}$ \\
\hline $\begin{array}{c}\text { Abertura e } \\
\text { comunicação }\end{array}$ & $\begin{array}{l}\text { Toda relação humana requer abertura e comunicação, toda } \\
\text { comunicação requer capacidade expressiva e compreensão por } \\
\text { parte do comunicante. A abertura e comunicação são as relações } \\
\text { interpessoais que ocorrem no âmbito escolar. }\end{array}$ \\
\hline
\end{tabular}

Fonte: Adaptado de $\mathrm{Hoz}$ (2018).

Esses critérios estabelecidos por $\mathrm{Hoz}$ (1990, 2018) podem ser encontrados através da análise das competências na Base Nacional Comum Curricular (BNCC), documento que define o conjunto de aprendizagens essenciais que todos os estudantes devem desenvolver ao longo das etapas e modalidades da Educação Básica (BRASIL, 2017). Dentre as dez competências presentes neste documento, observa-se os cinco critérios descritos por Hoz (2018) sobre a educação personalizada nelas (Quadro 2). 
QUADRO 2 - Relação entre os critérios e as competências na BNCC

\begin{tabular}{|c|c|}
\hline Critério & Competências identificadas \\
\hline Singularidade & Competências gerais 1 e 8. \\
\hline Criatividade & Competências gerais 2, 3 e 5. \\
\hline Autonomia & Competências gerais 6 e 10. \\
\hline Liberdade & Competências gerais 5 e 6. \\
\hline Abertura e comunicação & Competências gerais 4, 7 e 9. \\
\hline
\end{tabular}

Fonte: Os autores

É importante ressaltar, que em nenhum momento a BNCC realiza uma discussão sobre a educação personalizada, mas ao entender os critérios de Hoz (2018), é possível estabelecer relações entre eles e as competências. Por esse motivo, pode-se enfatizar que a educação personalizada está presente nas competências da BNCC (BRASIL, 2017). A educação personalizada é observada nas metodologias ativas, que surgem com o papel de potencializar o processo de ensino e aprendizagem. Principalmente no ensino híbrido que pode ser definido com um programa de educação formal que o estudante aprende por meio do ensino on-line, com algum elemento de controle do estudante sobre o tempo, lugar, modo e ritmo de estudo, tudo isso atrelado ao ensino presencial, na escola (CHRISTENSEN; HORN; STAKER, 2013; LEITE, 2017). Para Bacich, Neto e Trevisani (2015), o ensino híbrido configura-se como uma combinação metodológica que causa impacto na ação do professor em situações de ensino e na ação dos estudantes diante de sua aprendizagem.

\section{PERCURSO METODOLÓGICO}

De modo a alcançar o objetivo desta pesquisa que é investigar a presença da educação personalizada nas publicações de periódicos da área de Ensino da CAPES no período entre 2010 a 2020 que tratam sobre o ensino híbrido, analisando se as propostas nos artigos atendem aos critérios estabelecidos por Hoz (2018) sobre educação personalizada, indicando a presença ou ausência da personalização, realizou-se uma pesquisa exploratória, de cunho bibliográfica. Segundo Gil (2017, p. 26), pesquisas 
exploratórias "têm como propósito proporcionar maior familiaridade com o problema, com vistas a torná-lo mais explícito". Já Malheiros (2011, p. 81), aponta que uma das características da pesquisa bibliográfica é "identificar na literatura disponível as contribuições científicas sobre um tema específico", que no neste caso é a educação personalizada, de forma a localizar o que já foi pesquisado e confrontar seus resultados (MALHEIROS, 2011).

A coleta de dados foi fundamentada com base nas quatro etapas propostas por Lima e Mioto (2007), a saber: 1) Parâmetro temático: os artigos foram relacionados ao objeto de estudo (Personalização e Ensino Híbrido) buscando identificar se há e qual o tipo de educação personalizada está presente nos textos; 2) Parâmetro linguístico: seleção realizada em revistas de língua portuguesa. A escolha de revistas com publicações no idioma português se justifica pelo fato de buscarmos identificar características da educação personalizada no contexto das pesquisas realizadas principalmente no Brasil; 3) Principais fontes: Revistas com estrato A (A1 e A2) na avaliação do Qualis-CAPES na área de Ensino. O Qualis-CAPES é um sistema usado para classificar a produção científica dos programas de pósgraduação no Brasil (possui 8 classificações, sendo a A1 e A2 as classificações consideradas mais elevadas que um periódico pode receber); 4) Parâmetro cronológico: período a ser investigado é de 2010 a 2020. O período de pesquisa foi escolhido para que todos os quadriênios (quadriênio 2010-2012 e quadriênio 2013-2016) disponíveis na plataforma Sucupira (https://sucupira.capes.gov.br) fossem analisados. A escolha dos dois quadriênios deu-se para a obtenção de uma pesquisa mais ampla, podendo verificar se houveram alterações, ou seja, se surgiram ou deixaram de existir algum periódico ao longo desse tempo com Qualis A.

Após a seleção das revistas, foi realizada a busca dos artigos que apresentassem o ensino híbrido como foco do trabalho. Para isso, utilizou-se os descritores "ensino híbrido", "personalização do ensino" e "educação personalizada" e como escopo da busca a opção "todos". De modo a atender ao objetivo desta pesquisa foi realizada uma leitura dos resumos dos 
textos no intuito de identificar se estes apresentavam as discussões relacionadas a temática e quando não permitiam a sua identificação, realizou-se a leitura na íntegra dos textos.

Para análise dos artigos foram levados em consideração os critérios que Hoz (2018) aponta como essenciais para se planejar uma educação personalizada: Singularidade, Criatividade, Autonomia, Liberdade, Abertura e Comunicação. Para cada um desses critérios uma pergunta guia foi formulada (Quadro 3), de modo a contribuir para nossa análise. As perguntas foram elaboradas no intuito de permitir a visualização desses critérios presentes no artigo investigado e também para auxiliar futuros professores que desejem personalizar o ensino, assim poderão realizar esses questionamentos antes de aplicarem alguma metodologia para a personalização do ensino.

QUADRO 3 - Perguntas guia para análise de um ensino personalizado

\begin{tabular}{|c|l|}
\hline Critérios & \multicolumn{1}{|c|}{ Pergunta guia } \\
\hline SINGULARIDADE & $\begin{array}{l}\text { A construção da proposta/atividade foi baseada em } \\
\text { situações presentes no cotidiano do estudante? } \\
\text { Utilizou diversos recursos (digitais ou não)? } \\
\text { Levou em consideração as condições e experiências histórico- } \\
\text { sociais dos estudantes? }\end{array}$ \\
\hline CRIATIVIDADE & Foi permitido ao estudante criar ou expressar ideias? \\
\hline AUTONOMIA & O estudante se tornou autônomo em algum momento? \\
\hline LIBERDADE & O estudante teve a liberdade de escolha? \\
\hline ABERTURA & O estudante se expressou livremente? \\
\hline COMUNICAÇÃO & $\begin{array}{l}\text { Houve comunicação entre pares (professor-estudante e/ou } \\
\text { estudante-estudante)? }\end{array}$ \\
\hline
\end{tabular}

Fonte: Os autores

\section{RESULTADOS E DISCUSSÃO}

Os primeiros registros encontrados nesta pesquisa durante a seleção das revistas com Qualis A disponíveis na plataforma Sucupira mostravam um total de 434 revistas nos dois quadriênios (2010-2012 e 2013-2016), após o refinamento da busca para revistas em português (etapa 2), houve uma redução dos registros. Para evitar a duplicidade das revistas que estavam 
sendo contabilizadas nos dois quadriênios, organizou-se os dados se obtendo uma relação única de 101 revistas encontradas durante a pesquisa.

A busca dos artigos foi realizada nas 101 revistas, contudo apenas dez (10) apresentavam trabalhos sobre a temática. Nesse sentido, trinta (30) artigos foram observados nessas revistas e após a leitura apenas cinco (5) apresentavam a metodologia híbrida e suas modalidades (Quadro 4) sendo analisados à luz dos conceitos propostos por Hoz (2018).

QUADRO 4 - Artigos que apresentavam a metodologia híbrida

\begin{tabular}{|c|c|c|c|c|}
\hline Identificação & Título & Autores & Revista & Ano \\
\hline Artigo 01 & $\begin{array}{c}\text { Ensino híbrido e } \\
\text { educação ambiental: } \\
\text { uma intersecção possível }\end{array}$ & $\begin{array}{c}\text { GASPI, S.; } \\
\text { MAGALHÃES- } \\
\text { JÚNIOR, C. A. O. }\end{array}$ & $\begin{array}{l}\text { Contexto \& } \\
\text { educação }\end{array}$ & 2020 \\
\hline Artigo 02 & $\begin{array}{c}\text { Rotação por estações no } \\
\text { trabalho com equações } \\
\text { do } 2^{\circ} \text { grau: uma } \\
\text { experiência na } \\
\text { perspectiva do ensino } \\
\text { híbrido }\end{array}$ & $\begin{array}{c}\text { GUIMARÃES, D. } \\
\text { D.; JUNQUEIRA, S. } \\
\text { M.S. }\end{array}$ & $\begin{array}{l}\text { Educação } \\
\text { matemática } \\
\text { pesquisa } \\
\text { (online) }\end{array}$ & 2020 \\
\hline Artigo 03 & $\begin{array}{c}\text { Processo para } \\
\text { implementação da } \\
\text { metodologia da sala de } \\
\text { aula invertida com } \\
\text { elementos de } \\
\text { colaboração }\end{array}$ & $\begin{array}{l}\text { HONÓRIO, H. G. } \\
\text { G.; } \\
\text { SCORTEGAGNA, } \\
\text { L.; DAVID, J.M. N. }\end{array}$ & $\begin{array}{l}\text { Revista } \\
\text { brasileira de } \\
\text { ensino de } \\
\text { ciência e } \\
\text { tecnologia }\end{array}$ & 2019 \\
\hline Artigo 04 & $\begin{array}{l}\text { Processos de ensino e } \\
\text { aprendizagem de } \\
\text { Matemática em um } \\
\text { formato híbrido na } \\
\text { educação superior }\end{array}$ & $\begin{array}{l}\text { BERTOLUCI, E. A.; } \\
\text { SOUZA, A. R. }\end{array}$ & $\begin{array}{c}\text { Revista } \\
\text { diálogo } \\
\text { educacional }\end{array}$ & 2018 \\
\hline Artigo 05 & $\begin{array}{c}\text { Educação híbrida e } \\
\text { design instrucional: estudo } \\
\text { de caso no Ensino } \\
\text { Superior Tecnológico }\end{array}$ & $\begin{array}{c}\text { CASTRO, A. B. B.; } \\
\text { MILL, D. }\end{array}$ & $\begin{array}{c}\text { Revista } \\
\text { diálogo } \\
\text { educacional }\end{array}$ & 2018 \\
\hline
\end{tabular}

Fonte: Os autores

A análise dos artigos identificados nesta pesquisa foi realizada com base nas perguntas elaboradas no Quadro 03 que relaciona os critérios apontados por Hoz (2018) e as informações presentes nos artigos. Além disso, as perguntas podem auxiliar (futuros) professores que desejem personalizar o ensino de modo a realizarem esses questionamentos antes de aplicarem alguma metodologia que proponha a personalização do ensino. Cabe 
ressaltar que, por questão de limitações de páginas apresentaremos uma síntese dos achados nos artigos relacionando com os critérios de Hoz (2018).

\section{Singularidade}

A educação, do ponto de vista da singularidade deve fazer o sujeito consciente qualitativamente e quantitativamente de suas próprias possibilidades e limitações (HOZ, 2018). Nesse sentido, os artigos foram analisados a partir dos seguintes questionamentos para a Singularidade: A construção da proposta/atividade foi baseada em situações presentes no cotidiano do estudante? Utilizou diversos recursos (digitais ou não)? Levou em consideração as condições e experiências histórico-sociais dos estudantes? $\mathrm{Na}$ análise dos artigos apontamos como as propostas foram construídas, que recursos foram utilizados e se foram considerados as condições e experiências histórico-sociais. É importante ressaltar que levamos em consideração que as experiências histórico-sociais são os conhecimentos prévios dos estudantes, sua experiência enquanto seres vivos, nas relações humanas e nesse caso, o contato/acesso a alguns recursos de acordo com suas condições.

O artigo 01 apresentou um curso no formato híbrido com aplicação da metodologia sala de aula invertida, do modelo de rotação por estações e do modelo laboratório rotacional. Pode-se considerar que está proposta foi baseada em situações presentes no cotidiano dos estudantes. Primeiro porque a instituição para aplicação da metodologia híbrida foi escolhida levando-se em consideração a vivência da instituição e também dos estudantes nesse âmbito, em que a escolha deu-se porque os estudantes estavam acostumados com abordagens utilizando tecnologias, existindo uma preocupação com a experiência histórico-social. Segundo pela escolha do tema, que foi meio ambiente, tema bastante pertinente e que está presente na vida de todos, além disso os autores justificaram ao longo do trabalho, através da literatura, a importância do tema abordado no curso e, consequentemente, para os estudantes. Para aplicação da 
metodologia híbrida, os autores fizeram o uso de diversos recursos digitais (áudios, vídeos, jogos etc.), além de celulares, tablets e computadores.

Com relação a consideração das condições e experiências históricosociais dos estudantes, observa-se que foi levado em consideração na escolha da instituição, sendo descrito pelos estudantes ao responderem o questionário sobre os conhecimentos prévios em educação ambiental e o uso das tecnologias digitais, o que levou a um conhecimento de suas vivências. Além desse questionário, os estudantes preencheram uma planilha com os dados pessoais e forneceram informações relacionadas ao acesso à internet fora da escola.

No que diz respeito ao artigo 02 foi aplicado um modelo de rotação por estações com 18 estudantes. A escolha dessa metodologia híbrida foi baseada em situações presentes no cotidiano do estudante, pois é uma realidade que eles vivenciam (dificuldade em matemática) e que também foi levado em consideração as experiências histórico-sociais dos estudantes, pois essa escolha está baseada na vivência e aprendizado dos mesmos em relação a disciplina. Ao traçar um perfil dos estudantes o artigo 02 justifica a consideração das experiências histórico-sociais dos estudantes, uma vez que é um ponto crucial para que o ensino seja personalizado. Por esse motivo Hoz (2018) esclarece que há uma necessidade de um diagnóstico mais preciso possível que envolva todas as aptidões, conhecimentos, emotividades e interesses de cada estudante, tendo em vista que todos esses aspectos devem ser considerados na programação das atividades escolares. Em relação ao uso de recursos foi retratado o uso de recursos principalmente digitais como vídeos, jogos digitais, celulares, tablets e computadores.

Em relação ao artigo 03 a metodologia utilizada foi a sala de invertida. $\mathrm{Na}$ análise do texto os autores não retratam a sua importância, o que indica que estes não levaram em consideração as experiências histórico-sociais dos estudantes. Também não foi retratado nenhum questionário/entrevista sobre as condições de acesso a materiais digitais/internet para que a metodologia pudesse ser aplicada. Para Hoz (2018) o diagnóstico prévio é necessário, mas 
também não basta apenas o diagnóstico da personalidade, é preciso igualmente apresentar os problemas de conhecer e avaliar o entorno social, especialmente o familiar, que rege a vida e a educação dos estudantes.

O artigo 04 apresentou um curso no formato híbrido aplicado com 25 estudantes de graduação tecnológica na área de gestão empresarial, utilizando o Moodle como ambiente virtual de aprendizagem. O artigo não apresentou respostas no que diz respeito a utilização de situações presentes no cotidiano. Com relação aos recursos utilizados, foram empregados recursos digitais como vídeoaulas, textos em PDF, computadores e celulares e presencialmente os estudantes fizeram uso de material impresso para responderem provas.

O artigo 05 aplicou a metodologia híbrida com 15 estudantes de um curso superior tecnológico. Os questionários aplicados durante a pesquisa puderam traçar um perfil do aluno e suas dificuldades frente ao uso das TDIC para o planejamento da disciplina híbrida, ou seja, os autores levaram em consideração o contexto em que os estudantes estavam inseridos e suas experiências histórico-sociais na construção da disciplina. O diagnóstico, a partir de qualquer instrumento de coleta de dados é essencial para o aproveitamento total do estudante naquela atividade, pois é a partir dele que $o$ professor e o próprio estudante pode se deparar e fazer uma autoavaliação das suas capacidades e limitações. Em outras palavras, Hoz (2018) aponta que, o que o estudante é agora é condicionável ao que ele será, desse modo, o conhecimento prévio de si mesmo é a melhor essência para autoavaliação e consequentemente para motivar o aprendizado de acordo com a possibilidade, interesse e experiência de cada um. Em relação aos recursos (digitais), observou-se que foram utilizados Smartphones, sites de busca e sites para criação de: e-book, mapas mentais, programas para produção de apresentação.

\section{Criatividade}

Ao tratar sobre a criatividade visamos analisar qual o desenvolvimento criativo que os estudantes apresentaram nas metodologias híbridas 
propostas nos artigos. No âmbito da criatividade, segundo Hoz $(2018$, p. 45) é "um erro gravíssimo pensar que qualquer um pode realizar uma obra criadora sem um aprendizado prévio". Em outras palavras, não nascemos com habilidades criativas, a desenvolvemos, por esse motivo é imprescindível o incentivo da criatividade nas escolas e principalmente pelos professores.

No artigo 01, durante a aplicação da metodologia híbrida os estudantes puderam produzir textos e frases, criar histórias em quadrinhos a mão ou utilizando o computador e também produzir um documentário. Hoz (2018) aponta que todo material oferece estímulos à percepção, principalmente a atividade do estudante, além disso, o material tem grande valor como fator motivacional. É por esse motivo que, a escolha dos materiais a serem utilizados tem grande peso no interesse e atenção dos estudantes para aquele determinado conteúdo.

$\mathrm{Na}$ proposta do artigo 02, os estudantes puderam criar histórias em quadrinhos e Lapbook (um livro interativo construído pelo estudante), produziram vídeos e entrevistaram outros estudantes. As atividades criativas propostas no artigo permitem responder ao questionamento inerente a criatividade, ou seja, os estudantes puderam criar e consequentemente apresentar suas ideias em suas atividades criativas.

No artigo 03, os estudantes criaram um resumo teórico em um fórum de discussão. Neste sentido, foi possível aos participantes expressarem suas ideias (critério da criatividade presente). Essas atividades criativas compartilhadas podem se configurar como uma boa estratégia de ensino. Para Fleith (2001), na criatividade é necessário fornecer ao estudante um feedback informativo, relacionar os objetivos do conteúdo com às suas experiências e criar um espaço para divulgação dos trabalhos, que no caso de atividades compartilhadas isso já ocorre.

Em relação ao artigo 04 não foram observadas evidências de criações de materiais por parte dos estudantes. Já no artigo 05, os autores apresentam um quadro de modelagem de Design Instrucional o que permitiu identificarmos que os estudantes puderam criar um roteiro de 
produção de um vídeo, redigir e criar um E-book, elaborar mapas mentais, construírem uma apresentação oral e também um sarau de poemas. Foi perceptível nesse artigo, que criatividade foi estimulada contribuindo para o processo de construção do conhecimento, apesar de que, nos resultados os autores não apresentam dados claros sobre essas atividades criativas, isto é, os resultados só retratam que a criatividade seria um alvo na formação durante a disciplina.

\section{Autonomia}

Ao tratar da autonomia, $\mathrm{Hoz}$ (2018, p. 46) destaca que ela "é a capacidade do governo de si mesmo, a capacidade de ser lei de si mesmo, a posse e o uso efetivo da liberdade". Para Leite (2018, p. 590), a autonomia do estudante é oriunda de seu protagonismo, ou seja, de "sua capacidade de tomar decisão a respeito de seu próprio aprendizado". Nesse contexto, os artigos foram analisados com base no seguinte questionamento: os estudantes se tornaram autônomos em algum momento? É importante ressaltar que trazemos nessas análises conjecturas da presença da autonomia nas ações realizadas, o que significa dizer que é uma análise no sentido subjetivo e considerando alguns aspectos elencados pelos próprios autores dos artigos, até porque existem diversos graus de autonomia e não é trivial inferir com precisão se houve o desenvolvimento real da autonomia dos estudantes, pois para isso, seria necessário estar presente em todas as ações propostas por eles.

Os autores do artigo 01 relatam que se procurou centralizar os estudantes durante todo o processo na atividade, a fim de que esses pudessem expressar e discutirem as temáticas com seus pares, considerando o cotidiano vivenciado por eles, na escola, na casa ou na comunidade, com o intuito de tornar a aprendizagem mais significativa. Há relatos no artigo 01 que evidenciam a autonomia, em que a metodologia foi pensada para tornar o estudante protagonista. Todavia, é importante ressaltar que a autonomia pode ultrapassar o sentido do fazer só. Consolida-se, que a educação serve à autonomia do estudante e tem o papel de livrá-lo da 
ignorância, capacitando-o para conhecer e valorizar a realidade $(\mathrm{HOZ}$, 2018).

$\mathrm{Na}$ análise do artigo 02 foi registrado, pelos autores, que os estudantes tiveram autonomia de seguir realizando suas funções sem intervenções, cada um realizou o seu papel nos fragmentos do diário de bordo. A autonomia nos torna responsáveis por nossas próprias decisões e esse fator foi considerado nesse artigo, respondendo assim à questão guia. Para Freire (1996) nenhuma pessoa é autônoma primeiro para depois decidir. A autonomia se constrói na experiência de várias decisões que vão sendo tomadas.

No artigo 03 a autonomia dos estudantes pode ser apontada principalmente durante a utilização do AVA e também na aplicação da sala de aula invertida, em que eles tinham que estudar em casa sem a presença do professor. Durante a aula invertida a autonomia pode ser evidenciada nas ações dos estudantes (LIMA-JÚNIOR et al., 2017; OFUGUI; FIGUEREIDO, 2017; SILVA; SILVA NETO; LEITE, 2021). O texto indica que os estudantes se tornaram autônomos em algum momento, apesar de não enfatizar com clareza. Considerando que no trabalho foi utilizada uma metodologia ativa, é possível que pelo menos em alguns momentos os estudantes tenham tomado decisões e desenvolveram algum grau de autonomia. Ao utilizar as metodologias ativas o professor começa a exercer o papel de mediador, facilitando a implementação prática das metodologias que possibilitarão ao estudante adquirir sua autonomia durante todo o processo formativo (BERBEL, 2011; LEITE, 2018).

Em relação ao artigo 04, o grau de autonomia não ficou perceptível na leitura do texto e ao se realizar uma busca pela palavra autonomia no artigo, nenhum registro foi encontrado.

No artigo 5, os autores apontaram que o alvo de formação durante a realização da disciplina foi trazer características como colaboração, autonomia, curiosidade, responsabilidade e criatividade. Neste trabalho é enfatizado que ao utilizarem a metodologia híbrida, os autores quiseram promover a autonomia dos estudantes. Tal situação fica evidente no texto, 
pois as atividades propostas estavam elencadas na parte da criatividade deixando os estudantes livres para criarem e, consequentemente, desenvolveram um pensar e fazer mais autônomo. Como afirma Freire (1996), a autonomia é o amadurecimento para si, é um processo de vir a ser. A autonomia não tem hora marcada para ocorrer e é nesse sentido que uma pedagogia da autonomia deve estar centrada em experiências estimuladoras, respeitosas a liberdade, decisórias e de responsabilidade. A educação personalizada assume a responsabilidade de abranger as possibilidades de aprendizagens que devem ser inerentes a formação humana, com ou sem recursos digitais, para deficientes ou não, em todos os níveis de ensino, com base no princípio que a educação deve contribuir para o desenvolvimento humano nos aspectos cognitivos, sociais, históricos e outros.

\section{Liberdade}

Para análise da liberdade, utilizou-se como pergunta guia se "O estudante teve a liberdade de escolha?" Nesse sentido, consideramos tudo que não é imposto e autoritário é liberdade. Nas palavras de Freire (1996) liberdade no sentido de não autoritarismo. Para ele, a liberdade é amadurecida no confronto com outras liberdades. É decidindo que se aprende a decidir (FREIRE,1996). Por tanto, estamos analisando a liberdade em um sentido subjetivo, baseado no que está no texto e levando em consideração justamente o fato de decidir sobre algo, de opinar. Destaca Hoz (2018) que o caminho para perfeição do ser humano é atingindo pelas múltiplas possibilidades de agir livremente.

No artigo 01, os estudantes puderam participar das decisões do que seria desenvolvido durante a formação como descrito pelos autores que após a recepção dos estudantes foi realizada a apresentação do curso. Além disso, o texto destaca que foi possível explicitar a proposta de formação e o desenvolvimento das aulas híbridas, a fim de que eles (os estudantes) pudessem analisar e participar das decisões do que seria desenvolvido durante a formação. Na análise do artigo 02, percebe-se que 
os estudantes definiram seus papéis em cada estação presente na proposta do modelo de Rotações, além de escolherem o método de preferência para resolverem as questões de matemática. No artigo 05, os estudantes foram convidados a participarem voluntariamente, sendo-lhes esclarecidos os objetivos da pesquisa por meio de um Termo de Consentimento Livre e Esclarecido e além disso foram realizadas atividades que não tinham frequência computada, então eles poderiam escolher se participariam ou não (eram livres para escolher). Considera-se que os aspectos elencados nos artigos (01, 02 e 05) envolveram a liberdade de decisão e escolha por parte dos estudantes, por tanto, respondem com clareza a pergunta guia desta pesquisa. Por outro lado, é observável que os estudantes têm liberdade para participarem ou não de uma aplicação metodológica, aqui, analisamos o que está disposto nos textos.

Nos artigos 03 e 04 os autores não deixam claros a presença desse critério. Assim, é preciso destacar que dentro de uma proposta baseada na metodologia da sala de aula invertida e na EaD, os estudantes podem escolher qual horário vão assistir as aulas ou realizarem as atividades, inferindo na sua escolha/liberdade para aprenderem. Na educação personalizada, o estudante é alguém capaz de fazer o uso de todas as suas possibilidades mentais e práticas, além de todas as formas de expressão (HOZ, 2018). Freire (1996) argumenta que como professores lidamos com a nossa liberdade, ações e escolhas. Ademais, também lidamos com a nossa autoridade em exercício e consequentemente lidamos com a liberdade dos educandos, que devemos respeitar. O respeito a liberdade é imprescindível não apenas para uma educação libertadora, mas sim para a formação de sujeitos que respeitem as opiniões divergentes. A liberdade do sujeito o leva a ter abertura com os outros.

\section{Abertura}

Os relacionamentos sociais são realizados através da comunicação entre os indivíduos e essa comunicação só é possível quando o sujeito está aberto a ela, nesse sentido a Abertura é a expressão livre para os que estão a sua volta. Para Hoz (2018) a abertura pode ser compreendida como as 
relações sociais que respondem totalmente a espontaneidade do homem, por esse motivo, a realização das pessoas, enquanto seres humanos envolvem o paradoxo de uma incomunicabilidade absoluta no ser e, ao mesmo tempo, uma necessidade existencial de abertura aos outros, em outras palavras o ser não-social e o ser social. Diante disso, os artigos foram analisados com base na pergunta guia (o estudante se expressou livremente?) buscando identificar respostas inerentes a esses questionamentos nos artigos.

As respostas observadas, para o critério Abertura, nos artigos 01, 02 e 03 demonstraram a participação livre e expressiva dos estudantes. No artigo 01, os autores apontam a realização de debates e discussões sobre a temática abordada. O debate é uma forma te comunicação que consequentemente só pode ser realizada quando os estudantes se sentem suficientemente seguros para se abrirem, se expressarem e/ou darem suas opiniões. No artigo 02 a abertura foi observada através do uso de uma rubrica em que os estudantes deveriam fazer uma autoavaliação e avaliarem os colegas com relação as atividades propostas nas estações, ou seja, se eles realizaram ou não, tais atividades. Para que haja uma avaliação sobre o outro é necessário que haja abertura (HOZ, 2018), ou seja, é preciso que $\mathrm{O}$ avaliador se expresse em relação ao outro, por esse motivo consideramos que houve abertura. No artigo 03 os autores relataram que quanto mais os estudantes estudavam através da sala de aula invertida, mais se sentiam à vontade para interagir no fórum e compartilhar coletivamente o que aprenderam. Todas essas interações envolvem a expressão de ideias e consequentemente há abertura (HOZ, 2018).

No artigo 04 são apresentadas algumas falas dos estudantes sobre as atividades e interações do mediador on-line e presencial. Como foram expressões que o próprio autor ressaltou, consideramos que esse seria um ponto de abertura, pois os estudantes se expressaram livremente. Já no artigo 05 os estudantes puderam se expressar livremente, principalmente durante o feedback que foi realizado através de um questionário para 
coletar a apreciação dos estudantes com relação a disciplina no novo formato.

\section{Comunicação}

A Abertura leva a expressão e a expressão a comunicação. Assim, na comunicação o homem se depara com relações que são impostas pela existência de outros sujeitos com os quais têm necessariamente que relacionar, por isso existe a necessidade de educar o homem para esse tipo de convivência, ou seja, para as interações comunicativas com os outros sujeitos (HOZ, 2018). Assim, os artigos foram analisados considerando a pergunta guia relacionada com o questionamento para a Comunicação: Houve comunicação entre pares (professor-estudante e/ou estudanteestudante)?

Ressaltamos que a análise das comunicações diz respeito apenas as apresentadas no texto. Após a análise dos artigos, observamos que nos artigos 01, 02, 03 e 05 ocorreram a comunicação e a maioria delas foi permitida através do uso das tecnologias digitais. Gómez (1999), argumenta que as tecnologias devem ser um suporte para uma comunicação mais diversificada e educativa, pois podem aproveitar diversas linguagens, formatações e canais de produção para circulação de novos conhecimentos. Nesse sentido, nos trabalhos sempre que possível os estudantes trabalharam em equipes, participaram de debates e discussão, houve comunicação no AVA, quando esse era utilizado. Além disso, nos artigos 01 e 05 um grupo no whatsapp foi criado para facilitar a comunicação entre os pares. Existem múltiplas possibilidades de agrupamento dos estudantes, esses agrupamentos permitem as comunicações e estabelecem as relações humanas que são importantíssimas para o desenvolvimento pessoal e profissional dos mesmos (HOZ, 2018).

No entanto, no artigo 04 houve comunicação, porém ela foi baixa como relatado pelos próprios autores. Hoz (2018), explica que, a colaboração com os demais, sejam docentes ou discentes, é realizada de 
maneira distinta e a efetividade dessa colaboração está condicionada ao número de pessoas que constituem os grupos. Além disso, Abreu e colaboradores (2011) ressaltam que a colaboração e a comunicação vão de encontro a aprendizagem colaborativa, que faz uso de estratégias para o desenvolvimento de diversas competências (pessoais e sociais), por meio das quais os componentes das equipes são responsáveis, e isso impacta na sua aprendizagem e também pode impactar na aprendizagem dos outros.

Por fim, além dos artigos serem classificados e analisados a partir dos critérios apontados por Hoz (2018), realizamos um levantamento das palavras "personalização, personalização do ensino ou educação personalizada", com o intuito de verificar se os autores discutiam a personalização em seus artigos e se de fato a aplicavam. A relevância de citações ou referências sobre a educação personalizada ou a personalização do ensino, pode inferir que os autores sabem ou já leram sobre a temática, buscando em suas aplicações a própria personalização. Diante do exposto, os artigos 01, 03 e 04 não apresentaram nenhuma das palavras supracitadas ao longo de seus textos, tampouco utilizaram referências sobre esses temas. Apesar de não apresentarem citações ou referências sobre esses temas, o artigo $01 \mathrm{em}$ nossa análise, com base em Hoz (2018), conseguiu responder todas as questões guia (Quadro 3), o que implica inferir que dentro da estratégia proposta pelos autores ocorreu uma personalização do ensino. O artigo 05 apresentou a palavra personalização ao longo de todo o seu texto e o artigo 02 apresentou uma citação sobre personalização do ensino. Esses dois artigos, em nossa análise conseguiram também responder todas as perguntas guias, o que infere afirmar que eles apresentam indícios de que as ações propostas poderiam levar a uma personalização do ensino (mesmo que de forma não consciente pelos autores).

A análise geral dos artigos pode ser vista no Quadro 5, na qual apontamos que os artigos 01, 02 e 05 são os que apresentam características de uma educação personalizada, uma vez que ao responderem adequadamente as perguntas guias podem ser considerados trabalhos que foram capazes de desenvolver uma personalização do ensino na 
perspectiva proposta por Hoz (2018). Em contra partida os artigos 03 e 04 não conseguiram responder a todas as questões guias, sendo insuficientes as respostas ou não cumpridas.

QUADRO 5 - Análise geral dos artigos com base nas perguntas guias

\begin{tabular}{|l|c|c|c|c|c|}
\hline \multicolumn{1}{|c|}{ Critérios } & Art. 01 & Art. 02 & Art. 03 & Art. 04 & Art. 05 \\
\hline Singularidade & EP & EP & I & I & EP \\
\hline Criatividade & EP & EP & I & NC & EP \\
\hline Autonomia & EP & EP & I & NC & EP \\
\hline Liberdade & EP & EP & NC & NC & EP \\
\hline Abertura & EP & EP & EP & I & EP \\
\hline Comunicação & EP & EP & EP & I & EP \\
\hline
\end{tabular}

Legenda: Ensino Personalizado (EP), Insuficiente (I), Não cumpriu (NC)

Fonte: Os autores

\section{CONSIDERAÇÕES FINAIS}

Este artigo procurou identificar características de uma educação personalizada nas publicações da área de Ensino no período entre 2010 a 2020 que tratavam sobre o ensino híbrido, analisando se as propostas presentes nos artigos atendiam aos critérios (singularidade, criatividade, autonomia, liberdade, abertura e comunicação) descritos por Hoz (2018) sobre educação personalizada, indicando a presença ou ausência da personalização.

Considerando que a quantidade de artigos encontrados foi relativamente baixa, pois em um total de 101 revistas, apenas 10 continham artigos sobre a metodologia híbrida, ou seja, cerca de 10\%, e ao refinar a busca verificamos que em apenas 04 delas foram publicados um total de 05 artigos (que foram utilizados em nossa análise), é preciso mais publicações que envolvam o ensino híbrido e que direcionem para uma educação personalizada.

As perguntas guias permitiram a visualização dos critérios propostos por Hoz (2018) e podem auxiliar professores que desejem personalizar o ensino, de modo que eles realizem esses questionamentos antes de aplicarem 
alguma metodologia para a personalização do ensino. Além disso, o debate sobre a personalização não é trivial e assim se fez necessário analisar na literatura tal abordagem, em que nos pareceu pujante argumentar pela ótica de Hoz (2018) que apresentou uma visão sobre personalização há mais de três décadas, podendo ser considerado como um dos pioneiros na discussão desta temática. Nesse contexto, as perguntas guias foram construídas com o intuito de facilitar não só a análise dos artigos, mas também de deixar mais visível as proposições de Hoz (2018) no que tange a educação personalizada.

Alguns critérios se mostraram complexos para serem analisados, uma vez que não foi simples identificar nos artigos (sem levar em consideração a subjetividade) os conceitos de singularidade, autonomia e liberdade e abertura. Por outro lado, apesar das dificuldades foi possível realizar uma análise qualitativa minuciosa e apontar, dentre os artigos analisados, os que conseguiram personalizar o ensino (Artigos 01, 02 e 05). Os artigos 03 e 04 não conseguiram, nessa análise, demonstrar essa personalização, pois foram insuficientes ou não evidenciaram elementos que os classificassem como um ensino personalizado.

Por fim, os resultados desse trabalho indicam contribuições para se pensar a educação personalizada de forma mais prática, visando incorporála no fazer docente com o intuito de levar a uma aprendizagem mais ativa e significativa para os estudantes. Além disso, com esse trabalho ficou perceptível na análise dos artigos que o ensino híbrido ao ser atrelado a atividades baseadas em metodologias ativas contribui de maneira substancial para uma aprendizagem personalizada. Com isso, espera-se que esta pesquisa possa contribuir para os docentes que queiram personalizar o ensino utilizando o ensino híbrido como metodologia em sua prática docente, além de abrir possibilidades para que trabalhos futuros investiguem e debatam sobre a importância de uma educação personalizada.

\section{REFERÊNCIAS}


ABREU, J.; CLAUDEIVAN, L.; VELOSO, F.; GOMES, A. S. Análise das Práticas de Colaboração e Comunicação: Estudo de Caso utilizando a Rede Social Educativa Redu. Anais do XXII Workshop de Informática na Escola, Aracaju, 2011. Disponível em: https://brie.org/pub/index.php/wie/article/view/1965/1724. Acesso em: 07 jan. 2021.

BACICH, L.; NETO, A. T.; TREVISANI, F. M. Ensino Híbrido: personalização e tecnologia na educação. Porto Alegre: Penso, 2015.

BACICH, L.; MORAN, J. Aprender e ensinar com foco na educação híbrida. Revista Pátio, v. 25, p. 45-47, 2018.

BERBEL, N. A. N. As metodologias ativas e a promoção da autonomia de estudantes. Semina: Ciências Sociais e Humanas, Londrina, v.32, n. 1, p. 4540, 2011.

BRASIL. [BNCC (2017)]. BNCC: Base Nacional Comum Curricular. Brasília: Ministério da Educação, Secretaria de Educação Básica, 2017. Disponível em: http://basenacionalcomum.mec.gov.br. Acesso: 10 jan. 2021.

CHISTIANSEN, C. M.; HORN, M. B.; STAKER, H.; Ensino híbrido: uma inovação disruptiva? Uma introdução à teoria dos híbridos. p. 1-52, mai. 2013.

Disponível em: https://porvir.org/wp-content/uploads/2014/08/PT_Is-K-12blended-learning-disruptive-Final.pdf. Acesso em: 12 fev. 2021.

COLL, C. A personalização da aprendizagem escolar, uma exigência da nova ecologia da aprendizagem, 2018. Disponível em:

http://www.eduforics.com/br/personalizacao-da-aprendizagem-escolaruma-exigencia-da-nova-ecologia-da-aprendizagem/. Acesso em: 10 jan. 2021.

FLEITH, D. S. Criatividade: Novos conceitos e ideias, aplicabilidade à educação. Revista Educação Especial, n 17, p. 1-5, 2001.

FREIRE, P. Pedagogia da autonomia: saberes necessários à prática educativa. São Paulo: Paz e Terra, 1996.

GIL, A. C. Como elaborar projetos de pesquisa. 6. ed. São Paulo: Atlas, 2017.

GÓMEZ, G. O. Comunicação, Educação e Novas Tecnologias: Tríade do Século XXI.V Simpósio de Pesquisa em Comunicação da Região CentroOeste. Goiânia, Brasil. Universidade Federal de Goiás, 1999. Disponível em: https://www.revistas.usp.br/comueduc/article/view/37017/39739. Acesso em: 20 mar. 2021.

GUZIK, A. A educação moderna é personalizada. In: Young Digital Planet (Org.). Educação no Século 21: tendências, ferramentas e projetos para inspirar. São Paulo: Fundação Santillana, 2016, p. 1-68.

HOZ, V. G. Educação Personalizada. Campinas: CEDET, 2018.

HOZ, V. G. Tratado Educación Personalizada. Madrid: Rialp, S. A, 1990. 
KNAUTH, D. S. Reflexões sobre o ensino híbrido como uma inovação disruptiva para a educação. Revista observatório, v. 4, n. 3, p. $1112-1121$, mai. 2018.

LEITE, B. S. Ensino híbrido utilizando a Rede Social Edmodo: um estudo exploratório sobre as potencialidades educacionais para o Ensino de Química. Revista Brasileira de Ensino de Ciência e Tecnologia, v. 10, n. 3, p. 206-230, 2017.

LEITE, B. S. Aprendizagem Tecnológica Ativa. Revista Internacional de Educação Superior, v. 4, n. 3, p. 580-609, 2018.

LIMA-JÚNIOR, A. B. Educação Personalizada por um Sistema Tutor Inteligente. João Pessoa, 2018, 66f. Monografia (Pedagogia) - Centro de Educação, Universidade Federal da Paraíba/PB, 2018.

LIMA-JÚNIOR, C. G.; MEIRA, A. A. C.; OLIVEIRA; N. L.; SANTOS, G. F.; MONTEIROJÚNIOR, M. A. Sala de aula invertida no ensino de química: Planejamento, aplicação e avaliação no Ensino médio. Revista Debates em Ensino de Química, v. 3, n. 2, p. $199-145,2017$.

MALHEIROS, B. T. Metodologia da pesquisa em educação. Rio de Janeiro: LTC, 2011.

NUNES, A. A. S. A atualidade da educação freiriana. Revista Exitus, Santarém, v. 20, n. 3, p. 347-373, 2017.

OFUGUI, M. S.; FIGUEREDO, C. J. Desenvolvendo a autonomia do aprendiz de inglês como L2/LE com o auxílio da técnica da sala de aula invertida: um estudo de caso. Linguagem \& Ensino, Pelotas, v. 20, n. 2, p. 55-80, 2017.

PARKHURST, H. Education on the Dalton Plan. New York: E.P. Dutton \& Company, 1922. Consulted: Fourth edition: 1926. Disponível em: http://www.eduforics.com/br/personalizacao-da-aprendizagem-escolaruma-exigencia-da-nova-ecologia-da-aprendizagem. Acesso em: 19 ago. 2020.

SILVA, B. R. F.; SILVA NETO, S. L.; LEITE, B. S. Sala de aula invertida no ensino de química orgânica: um estudo de caso. Química Nova, v. 44, n. 4, p. 493-501, 2021.

VOLTZ, C. E. P.; ELICKER, A. T.; BATTISTELLO, V. C. M.; MARTINS, R. L.; BARBOSA, D. N. F. O papel do professor reflexivo no ensino híbrido. Seminário Internacional de Educação, Tecnologia e Sociedade: Ensino Híbrido. Revista Educacional Interdisciplinar, v. 8, n. 1, p. 1-10, 2019.

Recebido em: 02 de julho de 2021. Aprovado em: 30 de novembro de 2021 . Publicado em: 09 de dezembro de 2021. 